Cristine Dossin Bastos

FISCHER

Vanessa Daniele MOTTIN ${ }^{1}$

Márcia HEERDT ${ }^{1}$

Thiago FILADELFO

Victor Hermes CERESÉR ${ }^{1}$

Maria Teresa QUEIROLO' ${ }^{1}$

Mariangela Costa

ALLGAYER $^{1}$

\section{Correspondência para:}

Cristine Dossin Bastos Fischer, Hospital Veterinário da ULBRA, Av. Farroupilha, 8001, prédio 25, sala 204, Canoas-RS, 92425-900，(51) 3477-9214 Ramal 2662 Fax: (51) 3477-9284, e-mail: tinevet@terra.com.br

Recebido para publicação: 01/10/2008 Aprovado para publicação: 24/09/2009

\title{
Amblyomma dissimile (Acari: Ixodidae) em Hydrodynastes gigas (Squamata: Colubridae) no estado Mato Grosso do Sul, Brasil — Nota Prévia
}

\author{
1 - Curso de Medicina Veterinária da Universidade Luterana do Brasil, \\ Canoas-RS \\ 2 - Curso de Biologia da Universidade Federal da Bahia, Salvador-BA
}

\section{Resumo}

A Hydrodynastes giga, (Duméril, Bibron \& Duméril, 1854) vulgarmente conhecida como surucucu-do-pantanal, é uma serpente de grande porte, que ocorre no norte, centro-oeste, sudeste e sul do Brasil e que pode ser parasitada por ectoparasitos como os carrapatos do gênero Amblyomma. Em dezembro de 2007 foram coletados manualmente três carrapatos de uma serpente $H$. gigas no pantanal de Miranda, MS, Brasil (19 $\left.51^{\prime}-19^{\circ} 58^{\prime} \mathrm{S} ; 56^{\circ} 17^{\prime}-56^{\circ} 24^{\prime} \mathrm{W}\right)$. Os carrapatos foram armazenados e enviados para o Laboratório de Parasitologia do Hospital Veterinário da ULBRA, Canoas, RS, onde foi realizada a identificação de três machos da espécie Amblyomma dissimile. A presente nota faz o primeiro relato de $A$. dissimile parasitando serpentes da espécie $H$. gigas no pantanal de Miranda, MS, Brasil.
A Hydrodynastes giga (Duméril, Bibron \& Duméril, 1854) é uma serpente de grande porte, que pode atingir $250 \mathrm{~cm}$ de comprimento total. É também denominada surucucu-do-pantanal ou em tupi-guarani boipevaçu (boipeva = cobra chata; açu $=$ grande). A H. gigas é descrita no Peru, Paraguai, nordeste da Argentina e norte, centro-oeste, sudeste e sul do Brasil, principalmente na região do pantanal sulmato-grossense. Devido à baixa densidade populacional essa espécie é considerada vulnerável; sendo abatida com frequência pelo homem quando encontrada no campo. ${ }^{1}$

Os carrapatos podem parasitar diversos animais, entre eles os répteis, que incluem os ofídeos como as serpentes. Estes ectoparasitos utilizam seu aparelho bucal para fixar-se em seus hospedeiros; alguns injetam toxinas com a saliva que afetam o metabolismo do hospedeiro, ocasionando debilidade, decréscimo do hematócrito, paralisia e até a morte. ${ }^{2}$ Outros podem transmitir protozoários intraeritrocitários como o Hepatozoon sp. que também podem causar a morte dos animais. ${ }^{3}$ Os carrapatos podem localizar-se entre as escamas das serpentes, especialmente por baixo da cabeça, na cavidade ocular, região periocular, regiões lateral e dorsal do corpo, sendo mais numerosos no terço anterior da serpente; raramente estes parasitos são encontrados entre escamas ventrais. ${ }^{2}$

O gênero Amblyomma pertence à família Ixodidae, grupo Metastriata, cujos membros são denominados carrapatos duros, por causa da presença de um rígido escudo quitinoso que cobre sua superfície. São carrapatos grandes, geralmente ornamentados, cujas patas têm faixas coloridas; há olhos e festões. Os palpos e o hipostômio são longos e não há placas ventrais nos machos. $\mathrm{O}$ último artículo do palpo (artículo IV) é de posição ventral, situado em uma cavidade na extremidade distal do artículo III. Apresentam ainda a base dorsal do capítulo quadrangular a hexagonal (em algumas espécies pode ser subtriangular) e a placa espiracular geralmente em forma de vírgula, que está estão situada posteriormente ao quarto par de pernas. São carrapatos de três hospedeiros. A presença 
e a forma do sulco marginal nos machos é importante para o diagnóstico específico no gênero Amblyomma. ${ }^{4}$

O gênero Amblyomma está distribuído em grande extensão geográfica, abrangendo todos os continentes, com exceção da Antártida. Cerca de 110 espécies já foram descritas para este gênero em todo o mundo, sendo que metade dessas espécies se encontra nas Américas, poucas na Austrália, apenas uma na Europa e o restante entre a Ásia e a África. ${ }^{5}$ Segundo Aragão e Fonseca ${ }^{6}$, no Brasil ocorrem 33 espécies deste gênero.

A espécie Amblyomma rotundatum é comum no Brasil parasitando vertebrados de sangue frio ${ }^{2}$, assim como a espécie Amblyomma dissimili, carrapato de iguanas e que ocorre também nos Estados Unidos (Flórida), México, Antilhas, Colômbia, Venezuela e Argentina. No Brasil é citada no PA, MT, MS, AC, SP. ${ }^{7} \mathrm{O} A$. dissimile é uma espécie comum em répteis, parasitando mais de $60 \%$ dos ofídios, $72 \%$ dos sapos e $84 \%$ dos lagartos e iguanas do Panamá. ${ }^{8}$ Brum e Rickes ${ }^{9}$ encontraram $A$. dissimile em serpente sucuri no parque zoológico do Rio Grande do Sul e o Amblyomma fuscum foi relatado por Martins et al. ${ }^{10}$, parasitando um lagarto. Cançado $^{11}$ identificou $A$. dissimile em jabutis (Geochelonia carbonaria) e jararacas (Bothrops matogrossense) na região do pantanal sul.

O objetivo desta nota foi levar à comunidade científica o conhecimento de

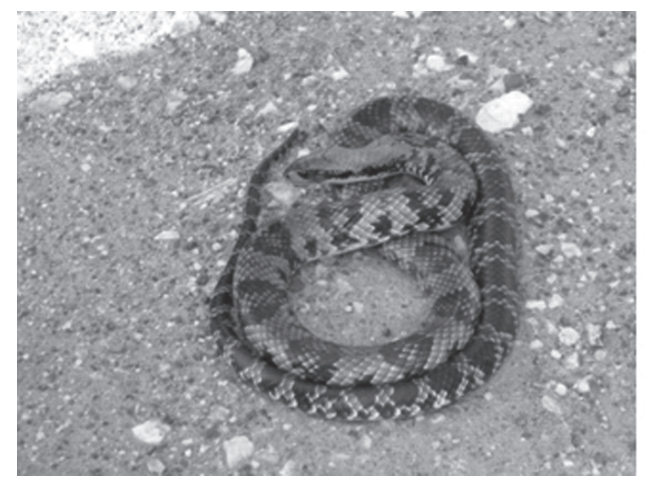

Figura 1 - Hydrodynastes gigas, vulgarmente denominada surucucu-do-pantanal, Pantanal de Miranda - MS, Brasil (20/12/ 2007)
A. dissimile parasitando uma serpente $(H$. gigas), colaborando com o enriquecimento de estudos na área de parasitologia veterinária, no pantanal de Miranda - MS.

Em dezembro de 2007 foram coletados manualmente três carrapatos da serpente $H$. gigas (Figura 1) de vida livre encontrada no pantanal de Miranda - MS,

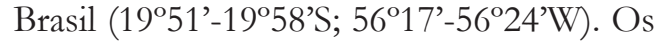
carrapatos estavam localizados entre as escamas na região dorsal do corpo no terço anterior da serpente (Figura 2). A serpente media $150 \mathrm{~cm}$ de comprimento, apresentava-se clinicamente saudável e logo foi liberada para seu habitat natural. Os carrapatos foram armazenados em frascos identificados, contendo álcool 70\%, e enviados para o Laboratório de Parasitologia do Hospital Veterinário da ULBRA, Canoas, RS.

Por meio de identificação ao estereomicroscópio foi possível identificálos como três carrapatos duros, com escudo quitinoso ornamentado que cobria toda a superfície dorsal, com os palpos e o hipostômio longos e sem a presença de placas ventrais, características compatíveis com machos do gênero Amblyomma. ${ }^{12}$ Segundo Barbosa et al. ${ }^{2}$, este gênero é comumente encontrado parasitando répteis e, Aragão ${ }^{13}$ relata que este carrapato já foi citado para os estados do Pará, Pernambuco e Mato Grosso, parasitando jibóia e iguana.

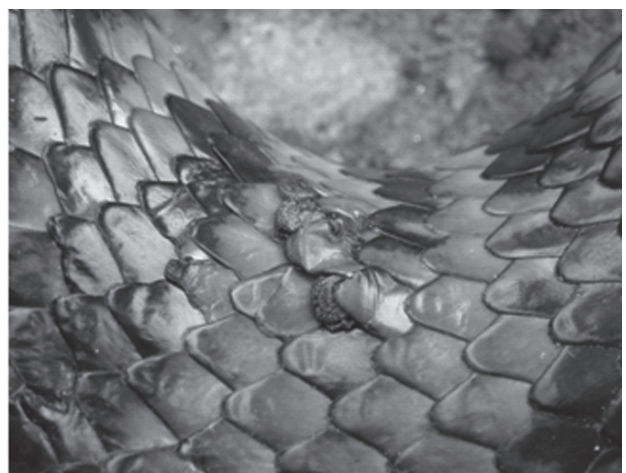

Figura 2 - Carrapatos da espécie Amblyomma dissimile localizados em serpente Hydrodynastes gigas entre as escamas na região dorsal do corpo no terço anterior, pantanal de Miranda - MS, Brasil (20/12/ 2007) 
Cançado $^{11}$ relata esta parasitose em jabutis e jararacas também no pantanal, MS. No Rio Grande do Sul, parasitando animais de sangue frio, foram citados Amblyomma fuscum, Amblyomma sculatum e Amblyomma sp. similarmente à Amblyomma goeldii em lagarto e $A$. rotundatum em jibóia. ${ }^{14}$

Posteriormente, realizou-se a identificação da espécie, o escudo apresentava coloração acobreada, revelando um pseudo-escudo na porção anterior e foram verificadas algumas pontuações maiores e menores de coloração mais claras em todo o escudo. Nos machos analisados havia ausência de sulco marginal; na coxa I com dois espinhos, curtos; coxas II e III com dois espinhos pequenos, o interno menor; as coxas IV, apresentavam dois espinhos, um interno curto e o espinho externo mais longo e com o ápice afilado. Estas características são descritas por Onofrio ${ }^{15}$ para a espécie A. dissimile, confirmando-se, portanto, se tratar de três machos da espécie $A$. dissimile.

Os exemplares de carrapatos foram encontrados parasitando uma serpente da espécie H. gigas, no estado do Mato Grosso do Sul, Brasil, estando de acordo com a área de distribuição geográfica descrita para esta serpente. ${ }^{1}$ A serpente encontrava-se em estado de higidez, mas Murray ${ }^{16}$ afirma que o $A$. dissimile pode transmitir nematódeos filarídeos dos gêneros Oswaldofilaria, Foleyella e Macdonaldius que quando adultos se localizam no sistema vascular dos répteis, podendo causar dermatite vesicular ou necrozante nos animais, além de anemia.

A localização dos carrapatos entre as escamas na região dorsal do corpo no terço anterior da serpente concordam com a citação de Barbosa et al. ${ }^{2}$ e Cançado ${ }^{11}$, que afirmam que os parasitos geralmente estão entre as escamas das serpentes, na região dorsal do corpo, sendo mais numerosos no terço anterior sendo raramente encontrados entre escamas ventrais.

Os carrapatos foram removidos manualmente, concordando com Lane e Mader $^{17}$, que sugerem a retirada manual de carrapatos quando estes estiverem em número limitado. Deve-se ter cuidado nesta remoção, já que se as peças bucais ficarem no hospedeiro, poderão favorecer uma infecção bacteriana secundária.

Cançado $^{11}$ afirma que a ixodofauna do pantanal ainda carece de estudos relacionando a biologia dos hospedeiros e de seus parasitas e fornece uma lista atual das principais espécies de carrapatos encontradas na região do pantanal sul do MS, incluindo o $A$. dissimile parasitando jararacas e jabutis. Contribuindo para ixodofauna do pantanal e do Brasil, a presente nota faz o primeiro relato de $A$. dissimile parasitando serpentes da espécie $H$. gigas neste Estado. A gama de ectoparasitas em animais silvestres é ampla e permite que novas espécies sejam incluídas como hospedeiros definitivos.

\section{Amblyomma dissimile (Acari: Ixodidae) in Hydrodynastes gigas (Squamata: Colubridae) in Mato Grosso do Sul State, Brasil - Short Communication}

\begin{abstract}
Hydrodynastes giga (Duméril, Bibron \& Duméril, 1854) best known as false water cobra, is a big-sized snake, which lives in Northern, Middlewestern, Southeastern and Southern Brazil and might be infested by ectoparasites, such as ticks from the Amblyomma genus. In December 2007 three ticks were manually collected from a H. gigas in the Miranda

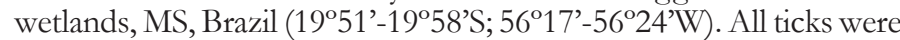
placed in identified bottles and then sent to the Laboratório de Parasitologia of ULBRA Veterinary Hospital, Canoas, RS, where the identification of three males of the Amblyomma dissimile species was carried out. This note is the first report of $A$. dissimile parasitizing snakes of the H. gigas species in the Miranda wetlands, MS, Brazil.
\end{abstract}

Key words:

Snake.

Hydrodynastes gigas.

False water cobra.

Tick.

Amblyomma dissimile. 


\section{Referências}

1 FONTANA, C. S.; BENCKE, G. A.; REIS, R. E. Livro vermelho da fauna ameaçada de extinção no Rio Grande do Sul. Porto alegre: Edipucrs, 2003. p.172173.

2 BARBOSA, A. R.; ALBUQUERQUE, H. N.; SILVA, H.; RIBEIRO, I. A. M. Contribuição ao estudo parasitológico de jibóias, Boa constrictor constrictor Linnaeus, 1758, em cativeiro. Revista de Biologia e Ciências da Terra, v. 6, n. 2, p. 1-18, 2006.

3 GLASER, V.; BONI, A. P.; ALBUQUERQUE, C. A. C. Ocorrência de Hepatozoon spp. (Apicomplexa, Hepatozoidae) em serpentes do gênero Bothrops de cativeiro- comunicação. Arquivo Brasileiro de Medicina Veterinária e Zootecnia, v. 60, n. 5, p. 1288-1290, 2008.

4 ONOFRIO, V. C.;LABRUNA, M. B.; PINTER, A.; GIACOMIN, F. G.; BARROS-BATESTTI, D. M. Comentários e chaves para espécie do gênero Amblyoma. In: BARROS-BATESTTI, D. M.; ARZUA, M.; BECHARA, G. H. Carrapatos de importância Médico-Veterinária da Região Neotropical: um guia ilustrado para identificação de espécies. São Paulo: Vox/ ICTTD-3/Butantan, 2006. p. 53-113.

5 ONOFRIO, V. L.; VENZAL, J. M.; PINTER, A.; SZABÓ, M. P. J. Família Ixodidae: características gerais, comentários e chave para gêneros. In: BARROSBATESTTI, D. M.; ARZUA, M.; BECHARA, G. H. Carrapatos de importância Médico-Veterinária da Região Neotropical: um guia ilustrado para identificação de espécies; São Paulo, ed. Vox/ICTTD-3/Butantan, 2006. p. 29-39.

6 ARAGÃO, H. B.; FONSECA, F. Notas de ixodologia. VIII: lista e chave para os representantes da fauna ixodológica brasileira. Memórias do Instituto Oswaldo Cruz, v. 59, n. 2, p. 115-129, 1961.

7 BOWMAN. D. D. Arthropods. In: BOWMAN, D. D.; LYNN, R.C.; GEORGI, J. R.; EBERHARD, M. L. Georgi 's Parasitology for Veterinarians. 9. ed. St. Louis: Elsevier, 2003. p. 1-82.

8 GUIMARÃES, J. H.; TUCCI, E. C.; BARROS-BATTESTI, D. M. Ectoparasitas de importância veterinária. São Paulo: Plêiade/FAPESP, 2001. p. 70-77.
9 BRUM, J. G. W.; RICKES, E. M. Amblyomma dissimile Koch, 1844 (Acari: Ixodidae) em serpente sucuri (Eunectes murinus) (Reptilia: Boidae) no parque zoológico do Rio Grande do Sul. Arquivo do Instituto Biológico, v. 70, n. 2, p. 215-216, 2003.

10 MARTINS, J. R.; MONTICELLI, E. C.; ONOFRIO, V. C.; BARROS-BATTESTI, D. M.; DOYLE, R. L. Primeiro relato de Amblyomma fuscum NEUMAN, 1907 (Acari: Ixodidae) parasitando lagarto da espécie Tupinambis teguinxin (L.), no município de Glorinha, Estado do Rio Grande do Sul, Brasil. Revista Brasileira de Parasitologia Veterinária, v. 16, n. 4, p. 246-247, 2007.

11 CANÇADO, P. H. D. Lista comentada das espécies de carrapatos e seus hospedeiros, selvagens e domésticos, encontradas no Pantanal Brasileiro. 2008. 22 f. Tese (Doutorado em Ciências Veterinárias) Instituto de Veterinária, Universidade Federal Rural do Rio de Janeiro, Rio de Janeiro, 2008.

12 URQUHART, G. M.; ARMOUR, J.; DUNCAN, J. L.; DUNN, A. M.; JENNINGS, F. W. Parasitologia veterinária. 2. ed. Rio de Janeiro: Guanabara Koogan, 1998. p. 123-178.

13 ARAGÃO, H. B. Ixodidas brasileiros e de alguns países limítrophes. Memórias do Instituto Oswaldo Cruz, v. 31, n. 4, p. 759-844, 1936.

14 EVANS, D. E.; MARTINS, J. R.; GUGLIELMONE, A. A. A rewiew of the ticks (Acari: Ixodidae) of Brazil, their hosts and geographic distribuation -1 . The state of Rio Grande do Sul, Southern Brazil. Memórias do Instituto Oswaldo Cruz, v. 95, n. 4, p. 453-470, 2000.

15 ONOFRIO, V. C. Revisão do gênero Amblyomma Koch, 1844 (Acari: Ixodidae) no Brasil. 2007. 174 f. Tese (Doutorado em Ciências Veterinárias) - Instituto de Veterinária, Universidade Federal Rural do Rio de Janeiro, Rio de Janeiro, 2007.

16 MURRAY, M. J. Cardiology and circulation. In: MADER, D. R. Reptile medicine and surgery. Philadelphia: W. B. Saunders Company, 1996. p. 95104.

17 LANE, T. J.; MADER, D. R. Parasitology. In. MADER, D. R. Reptile medicine and surgery. Philadelphia: W. B. Saunders Company, 1996. p. 185-203. 